\title{
Formação de professores de ciências em
} tempos de pandemia: uma estratégia de EAD sobre enfoques construtivistas e remotos do laboratório didático de ciências

Education of science teachers in pandemic times: a distance learning strategy on constructivist and remote approaches in science teaching laboratories

Ivana Elena Camejo Aviles ${ }^{1}$ Eduardo Galembeck²

\section{Resumo}

No contexto atual de excepcionalidade determinado pela pandemia do novo coronavírus, foi desenvolvida no Educational Technology Lab-UNICAMP uma pesquisa de mediação pedagógica, com perspectiva interpretativa e descritiva no intuito de ter evidências de aprendizagem de professores de ciências sobre enfoques construtivistas e remotos de ensino no laboratório didático de ciências. Neste sentido, propõem-se contribuir com os professores de ciências através da sua formação continuada em enfoques de abordagens construtivistas e remotos para elevar a qualidade da educação científica à distância, assumindo as potencialidades da experimentação remota devido a seu amplo potencial para auxiliar o processo de ensino de ciências à distância. Como parte dos resultados da aplicação da estratégia de educação à distância para a formação continuada dos professores, foi possível a identificação de evidencias de aprendizagem consistentes com as tendências construtivistas de ensino de ciências no laboratório didático.

Palavras chave: formação continuada do professor de ciências; abordagens construtivistas; enfoque epistemológico; aprendizagem significativa; experimentação remota; laboratório didático de ciências.

\section{Abstract}

In the current context of exceptionality determined by the pandemic of the new coronavirus, an educational mediation research was developed by the Educational Technology LabUNICAMP, with an interpretive and descriptive perspective, in order to have evidence of science teachers' learning on constructivist and remote approaches to teaching in the science teaching laboratory. The researchers propose to contribute to science teachers

\footnotetext{
${ }^{1}$ Universidade Estadual de Campinas | ivanacamejo_18@hotmail.com

${ }^{2}$ Universidade Estadual de Campinas | eg@unicamp.br
} 
through their continuing education in constructivist and remote approaches to raise the quality of distance science education, assumes the potential of remote experimentation due to its wide potential to help the process of teaching science at a distance. As part of the results of the application of the distance education strategy for the continuing education of teachers, it was possible to identify favorable conceptual changes consistent with current trends more widely accepted on the role of didactic experimentation in science teaching.

Keywords: continuing education of the science teacher; constructivist approaches; epistemological focus; meaningful learning; remote experimentation; science teaching laboratory.

\section{Introdução}

De acordo com um estudo desenvolvido pela FCC (2020), devido ao contexto de excepcionalidade determinado pela pandemia do novo coronavírus, os professores Brasileiros de Educação Básica ${ }^{3}$ vivenciaram um aumento considerável no desenvolvimento de atividades propriamente remotas, tais como: escrever e o responder e-mail, WhatsApp, SMS, trabalhar de casa nas atividades próprias da escola, participar de reuniões pedagógicas à distância, ministrar apoio ou suporte às famílias dos alunos, além de participar em cursos remotos de aperfeiçoamento profissional e ministrar aulas com recursos educacionais e ferramentas novas, das quais precisaram aprender no meio do caminho, tudo no intuito de reduzir o prejuízo educacional e de preservar o direito à educação.

Diversas instituições públicas e privadas levaram em consideração o desenvolvimento de estratégias de educação à distância $\left(\mathrm{EaD}^{4}\right)$ com a finalidade de auxiliar o professor na sua formação continuada de acordo com suas necessidades profissionais, emocionais, técnicas, entre outras. Assim, através da escola de extensão universitária da Unicamp, foram ofertados diversos cursos de extensão como o curso intitulado "Laboratório didático de ciências: construtivista e remoto", o qual representou uma tentativa de ampliação das ofertas de oportunidades oferecidas ao professor no momento de confinamento social.

Algumas das múltiplas preocupações do professor de ciências estão relacionadas com sua própria formação continuada no tocante à experimentação didática no ensino de ciências, a qual ainda hoje conserva um papel essencial insubstituível no processo de ensino de ciências, embora enfrente sérias debilidades que socavam sua reconhecida efetividade educacional (BORGES, 2002; FLORES, MOREIRA e CARABALLO, 2009, 2011; AUTOR 1 e AUTOR 2, 2020).

Segundo Santos, Ribeiro e Souza (2018), algumas das debilidades e problemáticas que bordeiam o laboratório didático de ciências (LDC) são os enfoques de ensino

\footnotetext{
3 Educação básica refere-se aos níveis das etapas de ensino: creche, pré-escola, fundamental I e II, ensino médio, ensino médio técnico, educação para jovens e adultos e educação especial.

${ }^{4}$ De acordo com o art. $1^{\circ}$ do decreto No 9.057, a EaD nesta pesquisa é entendida como a modalidade educacional na qual a mediação didático-pedagógica dos processos de ensino e aprendizagem ocorre através da utilização de meios e tecnologias de informação e comunicação, no qual os atores encontram-se em locais e momentos diferentes.
} 
tradicionalistas ${ }^{5}$, baseados na repetição de protocolos, centralizados no desenvolvimento da memorização como único processo cognitivo a potenciar nos estudantes, estreitamente relacionados com as acentuadas debilidades da formação inicial e continuada do professor de ciências, a precariedade da planta física dos laboratórios, a escassez de matérias e de reagentes, além do fato de ter uma suspensão de aulas presenciais durante o período de confinamento social, que levou os quase 48 milhões $^{6}$ de estudantes brasileiros a terem um ensino cem por cento remoto e à distância.

Com o intuito de contribuir no processo de construção de novos elementos teóricos e práticos, que, na opinião de Moreno e Massena (2020), poderiam somar esforços no processo de elaboração de posições epistemológicas frente ao conhecimento que é gerado na sala de aula para ter potencialmente uma sociedade mais crítica e responsável, esta pesquisa tenta atingir algumas das debilidades próprias do LDC, enfatizando na formação continuada do professor de ciências em abordagens construtivistas e de experimentação remota, sendo esta última, na opinião dos pesquisadores, uma estratégia didática de alto valor educacional com amplo espectro de alcance no cenário atual do confinamento social.

Neste sentido, esta pesquisa se orienta em responder o seguinte questionamento: que elementos teóricos e metodológicos devem ser levados em consideração numa estratégia de EaD desenvolvida no contexto pandêmico atual de confinamento para contribuir à formação continuada do professor de ciências em abordagens construtivistas e remotas de ensino no LDC? Porém os pesquisadores se propõem a auxiliar os professores de ciências através da sua formação continuada em enfoques de abordagens construtivistas e remotas do LDC com o intuito de elevar a qualidade da educação científica que, dia a dia, levam a seus alunos a apoiá-los para continuar levando um ensino de ciências remoto e de qualidade.

\section{FC de professores e EaD no cenário pandêmico atual}

Apesar da existência de uma ampla e variada oferta de cursos de pós-graduação e extensão das instituições particulares e públicas, ainda hoje os professores manifestam múltiplas necessidades na sua formação profissional que influenciam sua práxis pedagógica. De fato, no contexto pandêmico atual, uma pesquisa feita pelo Instituto Península (2020) apontou que os professores estão constantemente buscando na internet informações e apoio que permitam seu melhor desenvolvimento profissional, e que tenham uma procedência confiável, com conteúdo organizados e de qualidade.

A esse respeito, AUTOR 1 e AUTOR 2 (2020) ressaltam a importância de atingir as debilidades dos professores de ciências em abordagens construtivistas e remotas do LDC, no intuito não só de auxiliar o professor na sua formação, mas também para minorar as consequências derivadas do confinamento social, das disponibilidades de recursos dos

\footnotetext{
${ }^{5} \mathrm{O}$ enfoque tradicional do LDC representa, nesta pesquisa, uma perspectiva reducionista, porém antagônica aos acordos aceitos na atualidade sobre a natureza da ciência e seu processo de construção do conhecimento (Baroli, Luburu e Guridi, 2010; Flores, Caraballo e Moreira, 2009; André, Pesa e Moreira (2007); Hofstein e Lunetta, 2004; Bardera e Valdes, 1996; Hodson, 1994).

${ }^{6}$ Dados calculados com base no censo de 2018 do Instituto Nacional de Estudos e Pesquisas Educacionais Anísio Teixeira-INEP.
} 
laboratórios, da sua planta física, materiais e reagentes, entre outros, que afetam o desenvolvimento da experimentação didática e, consequentemente, do aprendizado de ciências.

Assim, as tendências atuais em pesquisas da área recomendam o desenvolvimento de estratégias de formação inicial e continuada do professor de ciências com abordagens de ensino alternativos, construtivistas como o enfoque investigativo e pela resolução de problemas reais e remotos, que favoreçam o aprendizado baseado no contexto escolar, além de técnicas, procedimentos e aplicação de protocolos (BORGES, 2002; FLORES, MOREIRA e CARABALLO, 2009, 2011; GRECA, MENESES e DIEZ, 2017; AUTOR 1, FLORES e AUTOR 2, 2020).

Desse modo, facilitar uma estratégia de EaD para a formação continuada do professor de ciências em enfoques construtivistas e remotos baseados na resolução de problemas reais no LDC poderia, consequentemente, na opinião de AUTOR 1 (2020), somar elementos positivos no processo complexo de desenvolvimento de noções de ciência nos estudantes, de maneira que eles sejam sensibilizados com a natureza eminentemente humana, consensuada, social, errática e dinâmica do processo de construção do conhecimento científico.

\section{Experimentação remota e enfoques construtivistas}

A Experimentação didática conserva ainda hoje um papel protônico que pareceria ser insubstituível no processo complexo de ensino de ciências. Alguns pesquisadores referemse à experimentação como fato essencial no processo de promoção de aprendizagens e no desenvolvimento de diferentes habilidades dos alunos. Assim, a atividade experimental tem o potencial de contribuir para o desenvolvimento do conhecimento científico, a partir da abordagem de questões relacionadas à observação e interpretação dos fenômenos, subsidiando a promoção de uma visão crítica da ciência, sempre que seja inserida através de enfoques e abordagens de ensino concomitantemente alternativos, construtivistas e epistemológicos (BORGES, 2002; FLORES, MOREIRA E CARABALLO, 2009, 2011; ANDRÉS, MENESES e PESA, 2007; AVILES e GALEMBECK, 2020; AVILES, FLORES E GALEMBECK, 2020; CACHICHI, GIROTTO, GALEMBECK, MOREIRA, FERREIRA, SIMONI, 2020).

$\mathrm{Na}$ atualidade, os professores de ciências enfrentam mais uma preocupação no médio confinamento social resultante da pandemia do novo coronavírus, já que encaram um ensino totalmente à distância, com poucas ferramentas didáticas para favorecer a experimentação no ensino de ciências. Neste sentido, concordamos com Silva, Bilessimo, Scheffer e da Silva (2020) em que o aprendizado síncrono não pode ser substituído, reconhecendo da mesma maneira as múltiplas impossibilidades que limitam o desenvolvimento de atividades experimentais nos laboratórios convencionais.

Portanto, anuímos com Silva, Bilessimo, Scheffer e da Silva (2020) sobre a visualização dos laboratórios remotos (LR) como laboratórios de experimentação reais, os quais são acessíveis e manipuláveis a partir da internet, com acesso irrestrito a qualquer momento e em qualquer lugar, adaptando-se deste modo às circunstâncias e necessidades dos usuários, e não o contrário, além de proporcionar conhecimento transversal, devido ao uso 
das $\mathrm{TDIC}^{7}$. Assim, o seguinte mapa conceitual expõe a posição dos pesquisadores sobre as potencialidades dos enfoques construtivistas como o epistemológico ${ }^{8}$ e remotos no processo de ensino de ciências no LDC no contexto atual:

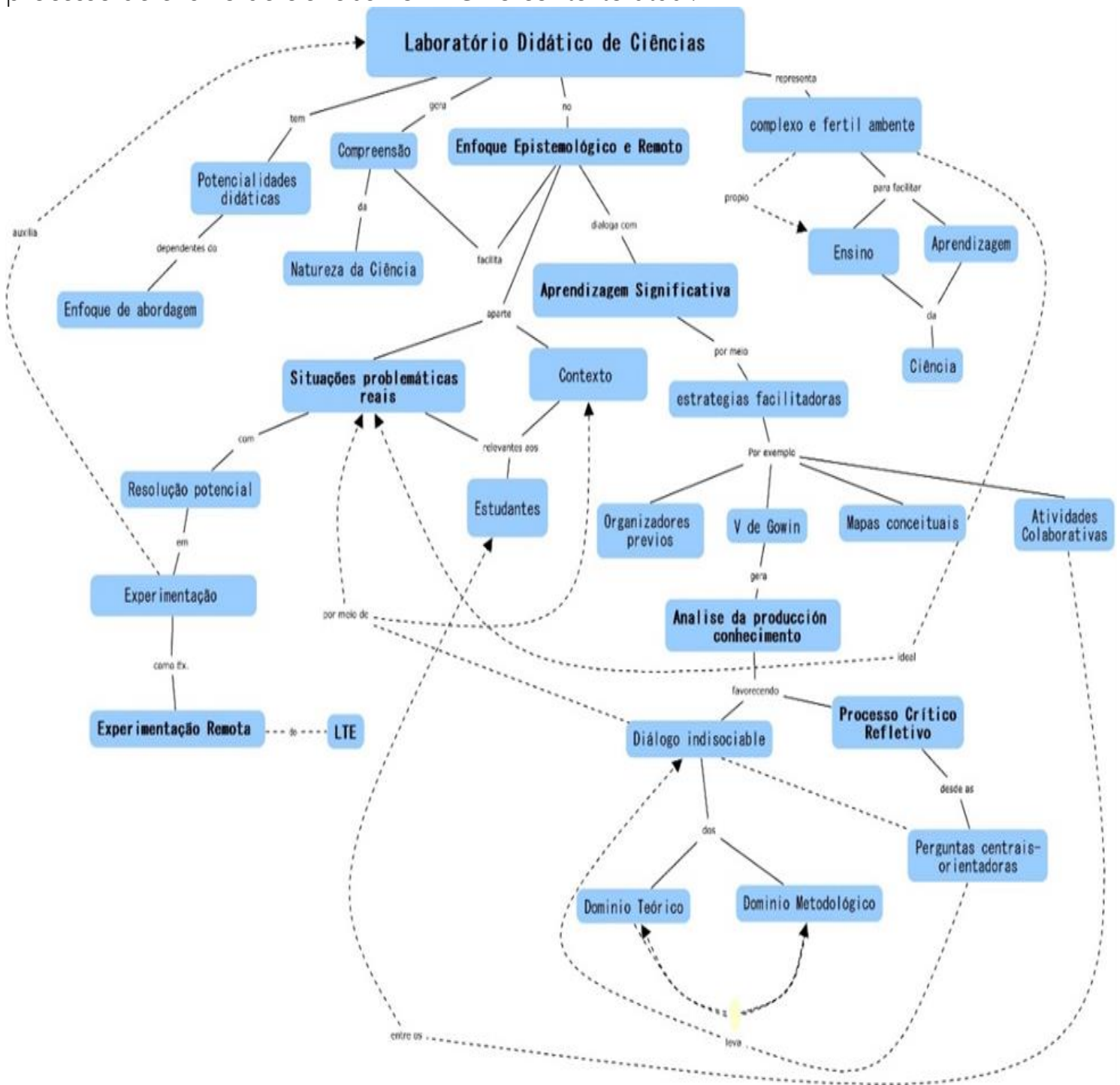

Figura 1- Laboratório didático de ciências com enfoque epistemológico e Remoto. Fonte: os pesquisadores.

Com efeito, os pesquisadores admitem as potencialidades da experimentação remota no intuito de atenuar as debilidades relacionadas com o confinamento social e desenvolvimento da experimentação no ensino de ciências, além das já referidas pela falta de recursos, matérias, reagentes, entre outros. Portanto, a pesquisa assume os benefícios da experimentação remota oferecida pelo Laboratório de Tecnologia Educacional ${ }^{9}$, devido ao

\footnotetext{
${ }^{7}$ Tecnologias Digitais da Informação e Comunicação.

${ }^{8}$ Enfoque de ensino de ciências no LD baseado na resolução de problemas de natureza socio-científicos com propostas de abordagens situadas em atividades experimentais.

${ }^{9}$ Educational Technology Lab-UNICAMP núcleo de pesquisa educativa que desenvolve diversas investigações da área de ensino e aprendizagens das ciências.
} 
seu amplo potencial para auxiliar o processo de ensino remoto de ciências no contexto pandêmico atual.

\section{Considerações metodológicas pedagógicas da pesquisa}

Esta pesquisa foi desenvolvida no centro de pesquisa 1-UNICAMP no meio do contexto determinado pela pandemia do novo Coronavírus, a qual levou os professores a lidar não só com suas próprias debilidades de formação inicial e continuada em suas dimensões disciplinares e pedagógicas, mas também a desenvolver um ensino totalmente à distância. Nesse sentido foi desenvolvido um estudo de mediação pedagógica, desde uma perspectiva interpretativa e descritiva com apoio em alguns parâmetros estadísticos, no intuito de ter evidências de aprendizagem de professores de ciências sobre enfoques construtivistas e remotos de ensino no LDC.

Contudo foi possível levar a cabo um processo de triangulação metodológica que permitiu a coleta de informações com a utilização de diversos métodos para tentar ter uma aproximação desde diferentes perspectivas sobre o nível processo de EaD para a formação de professores de ciências em enfoques construtivistas e remotos do LDC, no contexto pandêmico atual, atenuando na opinião de Denzin (1988, p. 318, citado por Moreira, 2011), as debilidades inerentes ao uso de um único instrumento no processo de coleta e análise das informações.

Os sujeitos participantes nas diferentes fases desta pesquisa foram em conjunto dezesseis professores de ciências com formações das áreas de biologia, física e geologia, inscritos no curso de extensão de dezesseis semanas intitulado "Laboratório didático de Ciências: construtivista e remoto" oferecido pela escola de extensão da Unicamp em 2020 como iniciativa para atingir a demandas dos professores sobre EAD no ensino de Ciências no meio da Pandemia. Esse grupo heterogêneo de professores atua nas redes públicas e particulares de ensino do Brasil, nos diferentes níveis de educação básica: ensino fundamental I e II, ensino médio, ensino técnico e graduação. Estes participaram nas diferentes etapas da pesquisa que são descritas a continuação.

Os elementos levados em consideração para o processo de triangulação metodológica das informações coletadas foram as evidências de aprendizagem significativa dos professores de ciências sobre o enfoque epistemológico e remoto do LDC, lembrando que este pesquisa não pretende delinear uma forma única de ensino potencialmente significativa na formação continuada dos professores de ciências, más sim apresentar como estas diferentes estratégias foram combinadas e analisadas no intuito de facilitar uma aprendizagem significativo dos professores participantes deste estudo. Nesse sentido, o registro das informações, aplicações de instrumentos e sua forma de sistematização e analises foi realizada de acordo com os seguintes instrumentos:

a. Questionário inicial: constituído por três itens abertos, previamente validados por especialistas, aplicados no início do curso para ter uma aproximação às ideias prévias e posicionamentos dos professores em relação à percepção das potencialidades dos LR no ensino de ciências, em conjunto com suas possibilidades de inserção na sua rotina escolar no contexto pandêmico atual. As informações aqui coletadas serão sistematizadas de acordo com as cinco fases do Analisis de conteúdo propostas por Moraes (2003). 
b. Mapas conceituais: considerados neste estudo como instrumentos de recolecção de informação com amplas potencialidades para exteriorizar possíveis mudanças nas ideias e percepções dos professores participantes sobre os enfoques de abordagens construtivistas e remotos dos LDC. Assim, AUTOR 1 e AUTOR 2 (2019) os mapas conceituais podem gerar contribuições importantes no processo de expansão da base interpretativa deste estudo, evidenciando aspectos pontuais que provavelmente não seriam percebidos desde a aplicação de um único instrumento. Os professores participantes deste estudo receberam as orientações necessárias no processo de construção de mapas conceituais de acordo com Novak, e Cañas (2010) e Moreira (2012). Os mapas conceituais neste estudo foram construídos no software gratuito Cmap Tools, versão 6.03.

c. Unidades Educacionais Potencialmente Significativas (UEPS): com base nas orientações de Moreira (2013), os professores participantes receberão os lineamentos para construir, ao longo da aplicação da estratégia de EaD, diversas versões das UEPS sobre os enfoques construtivistas e remotos do laboratório didático de ciências, levando em consideração seu contexto real atual de atuação pedagógica, através de um processo contínuo consultivo e de socialização entre pares com apoio dos professores-pesquisadores.

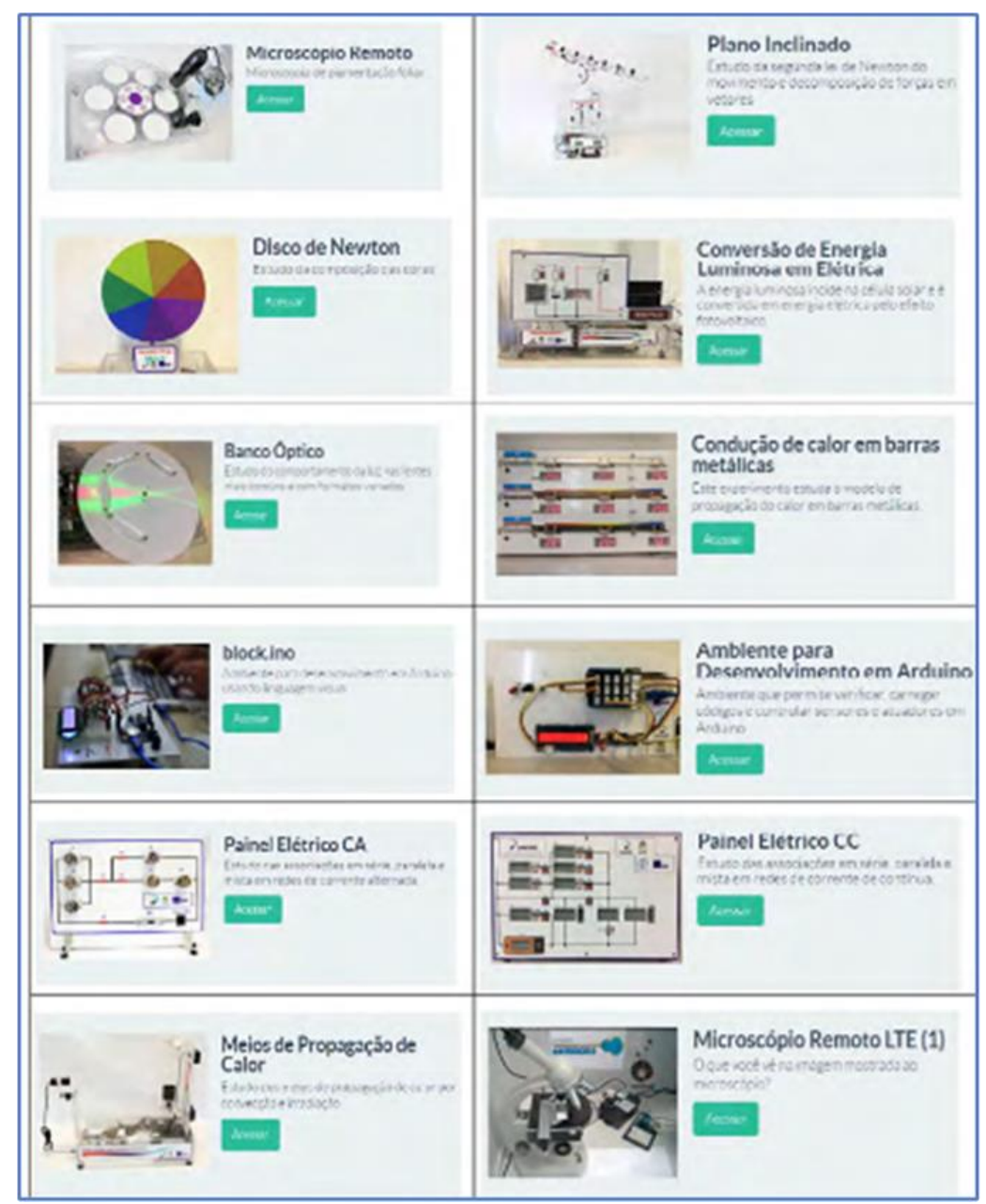

Figura 2- Alguns dos experimentos remotos disponibilizados nas plataformas do Education Tegnology Lab -Unicamp (LTE) e Laboratório de Experimentação Remota (RexLab). Fonte: LTE e RexLab.

Tomado em 2020 de http://relle.ufsc.br/labs 
O curso de extensão oferecido pela escola de extensão da Unicamp representou, nesta pesquisa, a estratégia de EaD para a formação continuada do professor de ciências em enfoques de abordagens do LDC construtivistas e remotos. A figura 2 representa alguns dos experimentos remotos que foram disponibilizados para os professores participantes do curso através das plataformas do Education Tegnology Lab -Unicamp (LTE) e Laboratório de Experimentação Remota (RexLab) ${ }^{10}$.

A estratégia de EaD foi desenvolvida na plataforma de aprendizagem Moodle $e^{11}$ e conta com as orientações didáticas sugeridas por Aviles, Flores e Galembeck (2020). Foi possível ter um encontro síncrono semanal de duas até três horas durante dezesseis semanas, além do tempo de assessoramento síncrono no processo de construção de mapas conceituais e UEPS, que variou, em cada professor, de trinta minutos até uma hora e meia cada semana. Adicionalmente os professores tinham encontros assíncronos na plataforma de aprendizagem Moodle para interatuar com diversos materiais educacionais sobre o enfoque epistemológico e remoto no laboratório didático de ciências. Alguns dos módulos e matérias educacionais proporcionados pelos pesquisadores através deste curso são apresentados na continuação:



Figura 3. Representação gráfica dos módulos que fazem parte da estratégia de EaD para a formação continuada do professor de ciências em enfoques construtivistas e remoto. Fonte: os pesquisadores

\footnotetext{
${ }^{10}$ Laboratório de experimentação remota da Universidade Federal de Santa Catarina (UFSC).

${ }^{11}$ Plataforma online de aprendizagem especialmente feita no intuito de que professores e estudantes podam num só sistema gerenciar de maneira integrada todos os elementos próprios do processo de ensino e aprendizagem.
} 


\section{Resultados e discussão}

As informações coletadas nesta pesquisa foram sistematizadas em três direções de analises: percepções inicias dos professores sobre a experimentação remota no ensino de ciências no cenário pandêmico atual; papel da experimentação didática no ensino de ciências; e evidencias de aprendizagem do enfoque epistemológico e remoto do ensino de ciências, assim, os resultados serão apresentados observando estas três grandes direções de recolecção das informações e de suas análises.

\section{Experimentação remota e ensino de ciências no cenário pandêmico atual: percepções iniciais dos professores.}

A análise de conteúdo desenvolvida com base nas ideias prévias e proposições subministradas pelos professores sobre sua percepção das potencialidades do LR no ensino de ciências no cenário pandêmico atual derivou na construção do gráfico 1, no qual são apresentadas e relacionadas as três categorias de análises e seus indicadores de frequência nominadas: cenário pandêmico, oportunidades na FC e disponibilidade/ acessibilidade de recursos.

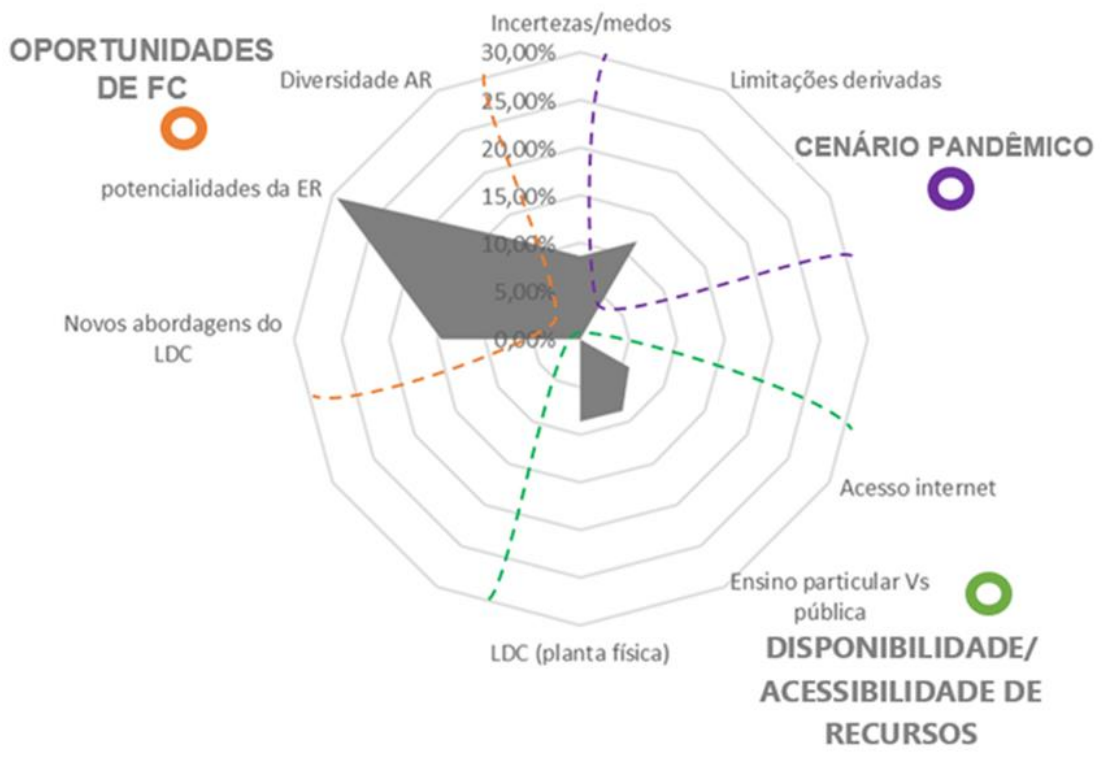

Gráfico 1- Ideias prévias dos professores sobre as potencialidades dos LR no cenário pandêmico atual. Fonte: os pesquisadores com base à sistematização dos dados.

A categoria nominada cenário pandêmico está determinada pelos indicadores incertezas, medos e limitações derivadas pelas frequências de 8,62\% e 11,76\%, respectivamente. Assim foi possível identificar a necessidade dos professores de resguardar sua vida no momento atual, valorizando o confinamento social como ferramenta de contenção na propagação do novo coronavírus. Da mesma maneira, os professores estão preocupados pela continuidade da educação na modalidade à distância, e manifestaram que as condições favorecem o aproveitamento das potencialidades de atividades de experimentação remota para auxiliar sua práxis pedagógica.

A categoria referida à disponibilidade e acessibilidade de recursos foi determinada pelos indicadores de acesso à internet, diferenças do ensino particular e público em termos de acesso a recursos, e precariedade das plantas físicas dos LDC. Em relação com estes 
resultados, um estudo desenvolvido pelo Instituto Península, publicado em 2021, indica que, no cenário atual pandêmico, 3 de cada 4 professores brasileiros acreditam que seu papel é de interagir remotamente com os alunos, não obstante, encontram três grandes obstáculos que desafiam sua função: a falta de infraestrutura para manter um EaD; a dificuldade para engajar os alunos; e sua falta de formação inicial e continuada que, em conjunto, influenciam negativamente o processo de ensino remoto.

A categoria com mais frequências foi a oportunidade de formação continuada, determinada pelos indicadores: necessidade do professor em conhecer novas abordagens de ensino de ciências no LDC (1,76\%); pela sua preocupação em ter uma diversidade de atividades remotas que possam auxiliar sua práxis docente (14,53\%); e potencialidades da Experimentação Remota no cenário pandêmico atual (29,50\%). Na opinião dos pesquisadores, esta categoria reúne os elementos que têm maior peso na tomada de decisões do professor de ciências no processo de busca e escolha de ofertas acadêmicas que fortaleçam sua FC.

A esse respeito, pesquisadores como Silva, Bilessimo, Scheffer e da Silva (2020); Aviles, , Flores e Galembeck (2020), Aviles e Galembeck (2020) concordam no potencial dos LR no processo complexo de promoção de aprendizagem significativa, autônoma e democrática, destacando ainda a importância da interatividade derivada da incorporação das tecnologias digitais da informação e comunicação no processo de estimulação entre os alunos, gerando consequentemente melhorias educacionais.

\section{Papel da experimentação didática no ensino de ciências: Aprendizagem Significativa dos Professores}

Tabela 1: instrumento de avaliação quantitativa dos mapas conceituais construídos pelos professores sobre o papel da experimentação didática.

\begin{tabular}{|c|c|c|}
\hline Aspectos a serem avaliados & Escala de Estimação & Ponderação (X/10pts) \\
\hline $\begin{array}{l}\text { Número de conceitos relevantes } \\
\text { ao papel da experimentação } \\
\text { didática no ensino de ciências }\end{array}$ & 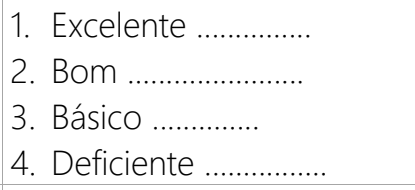 & $\begin{array}{r}\ldots . .5 p t s \\
\ldots \ldots .3 p t s \\
\ldots \ldots .2 p t s \\
\ldots \ldots \ldots .1 p t o\end{array}$ \\
\hline $\begin{array}{l}\text { Hierarquia entre os conceitos/ } \\
\text { extensão }\end{array}$ & $\begin{array}{l}\text { 1. Apropriadas ................ } \\
\text { 2. Elementais .............. } \\
\text { 3. inapropriadas ............. }\end{array}$ & $\begin{array}{l}\ldots \ldots .1 \text { pto } \\
\ldots \ldots . . .0,5 \text { pts } \\
\ldots \ldots \ldots . .0 \text { pts }\end{array}$ \\
\hline Frases de ligação & 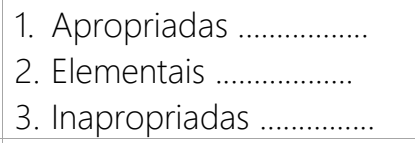 & 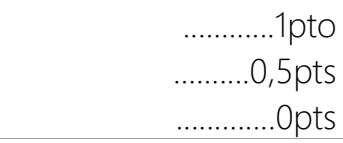 \\
\hline Relações cruzadas & $\begin{array}{l}\text { 1. Apropriadas...................... } \\
\text { 2. Inapropriadas/ausentes.. }\end{array}$ & $\begin{array}{l}\ldots \ldots \ldots .2 p t s \\
\ldots \ldots \ldots . .0 p t s\end{array}$ \\
\hline Adição de exemplos & $\begin{array}{l}\text { 1. Apropriados.................... } \\
\text { 2. Inapropriados/ausentes.. }\end{array}$ & $\begin{array}{l}\text {.............1pto } \\
\ldots \ldots \ldots \ldots . .0 p t s\end{array}$ \\
\hline
\end{tabular}

Foi feita uma análise quantitativa em cada uma das versões dos mapas conceituais construídos pelos professores do curso baseados nos critérios de análise foram adaptados dos propostos por Flores, Caballero e Moreira (2014); AUTOR 1 e AUTOR 2 (2019) e AUTOR 1, Flores e AUTOR 2 (2020). Assim foi feita uma estimação quantitativa da qualidade dos mapas conceituais nas suas versões 1, 2 e 3 (tabela 1), que levou a uma estimação global da 
construção dos mapas conceituais. Lembrando que a distribuição da ponderação e a construção da escala de estimação apresentadas na tabela 1 responde particularmente aos mapas conceituais construídos pelos sujeitos participantes desta pesquisa.

Associada à tabela 1, foi construída a seguinte tabela 2 que sintetiza a estimação global dos mapas conceituais construídos pelos professores sobre o papel da experimentação didática no ensino de Ciências, assim foram levados em consideração os elementos fundamentais no processo de construção de mapas conceituas, porém, dita estimação de qualidades refere-se especificamente aos mapas construídos pelos sujeitos deste estudo.

Tabela 2: estimação global de qualidade dos mapas conceituais construídos pelos professores sobre o papel da experimentação didática no ensino de ciências.

\begin{tabular}{|c|c|c|}
\hline Ponderação (X/10pts) & Estimação de qualidade & Abordagem didático no LDC \\
\hline De 9pts até 10pts & Excelente qualidade & $\begin{array}{l}\text { Abordagens do laboratório } \\
\text { didático construtivista, } \\
\text { epistemológico e remoto }\end{array}$ \\
\hline De 6 pts até 8 pts & Boa qualidade & $\begin{array}{l}\text { Abordagens de ensino no LDC } \\
\text { construtivista e remoto }\end{array}$ \\
\hline De Opts a 5 pts & Baixa qualidade & Abordagens tradicionalistas. \\
\hline
\end{tabular}

Neste ponto da pesquisa, um mapa com estimação de excelente qualidade de acordo com FLORES, SAHELICES E MOREIRA (2007) refere-se aqueles construídos no marco de tendencias alternativas, relativistas, ou seja, baseados em conceitos que com ampla afinidade com abordagens do laboratório didático construtivista, epistemológico e remoto. Assim um mapa de boa qualidade reúne elementos que dialogam com tendências e abordagens de ensino no LDC construtivista e remoto. Porém, um mapa conceitual identificado de baixa qualidade é aquele que contém elementos tendentes às posições e abordagens tradicionais de ensino de ciências no LDC convencional.

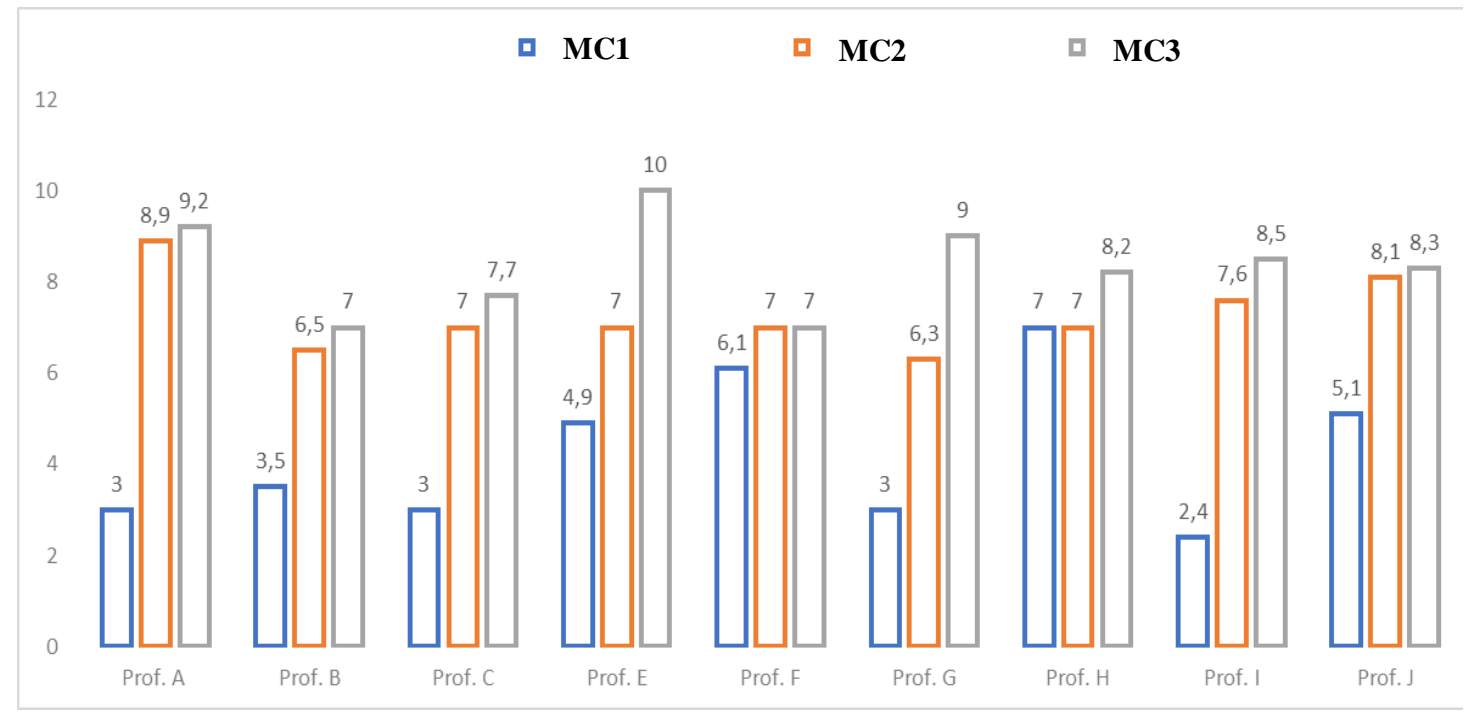

Gráfico 2. Estimação e correlação de qualidade dos mapas conceituais construídos pelos professores sobre o papel da experimentação didática epistemológica e remota no ensino de ciências. MC1 (primeira versão do mapa conceitual), MC2 (segunda versão do mapa conceitual) e MC3 (terceira versão do mapa conceitual). Fonte: os pesquisadores. 
Nesse sentido, o gráfico 2 apresenta e correlaciona a estimação de qualidade dos mapas conceituais com base nas versões 1, 2 e 3 construídos por nove dos professores participantes. Por motivos diversos, o resto dos professores participantes neste ponto da pesquisa só apresentaram uma ou duas versões dos mapas conceituais, fato que na opinião dos pesquisadores poderia interferir negativamente na base interpretativa desde estudo, porém embora contenham informação valiosíssima, não foram levados em consideração nesta parte específica do analises.

As informações referidas à MC1 do gráfico 2 representaram um elemento norteador fundamental da pesquisa, sendo o ponto de partida da orientação didática desenvolvida pelos pesquisadores através da estratégia de EaD para favorecer a aprendizagem significativa de enfoques construtivistas e remotos no ensino de ciências. Nesse sentido, as ideias prévias exteriorizadas na primeira versão dos mapas conceituas construídos pelos professores foram fundamentais no processo de formação contínua dos professores de ciências. Em coerência com Flores, Caballero e Moreira (2014), ter uma aproximação das ideias prévias dos estudantes sobre o tema a ensinar determina totalmente o sucesso no processo de construção de sentidos, da sua progressividade conceitual e na modificação das subsunções.

Nesse sentido, a meia da estimação quantitativa dos MC1 de $\bar{X}$ 4,2/10 pontos deixa esta primeira construção no nível de mapas conceituais de baixa qualidade o que nesta pesquisa significa que os MC apresentariam uma tendência marcante aos enfoques tradicionalistas de ensino de ciências no laboratório didático, o que concebe uma perspectiva reducionista e por tanto antagônica de acordo com a natureza da ensino de ciências no laboratório didático, baseados nas tendencias atuais e acordos mais amplamente aceitos na área (BAROLI, LUBURU E GURIDI, 2010; FLORES, CARABALLO E MOREIRA, 2009; ANDRÉ, PESA E MOREIRA (2007); HOFSTEIN E LUNETTA, 2004; BARDERA E VALDES 1996; HODSON 1994)

Assim, as séries correspondentes aos dados da construção dos mapas conceituas MC2 ( $\bar{X} 7,2 / 10)$ e MC3 ( $\bar{X}$ 8,4/10) indicam uma relação proporcional estreitamente relacionado com o nível de complexidade e evolução das subsunções, processo que é relacionado pelos pesquisadores com a participação ativa dos professores no desenvolvimento da estratégia de $\mathrm{EaD}$ e consequente apropriação dos enfoques construtivistas e remotos do ensino de ciências no laboratório didático de ciências. A esse respeito, Flores, Caballero e Moreira (2014) consideram que o processo de evolução das subsunções é indicador do processo de desenvolvimento das relações entre os diferentes conceitos, a incorporação de novos conceitos e novos sentidos, fato que favorece o processo de abstração do conhecimento e de reconciliação integrativa num processo ordenado de aprendizagem significativa.

\section{Nível de apropriação do enfoque epistemológico e remoto no ensino de ciências: as UEPS construídas pelos professores}

Neste ponto foram analisadas as duas versões das unidades educacionais potencialmente significativas (UEPS) construídas por oito ${ }^{12}$ dos professores participantes em

\footnotetext{
12 Por motivos diversos, oito professores participantes neste ponto da pesquisa só apresentaram uma versão da UEPS, fato que não deixa de ser interessante e relevante, mas insuficiente na opinião dos pesquisadores no processo de analises interpretativa desde estudo, porém, foram levados em consideração apenas as UEPS apresentadas nas versões 1 e 2 pelos outros oito professores.
} 
dois momentos diferentes durante o desenvolvimento da estratégia de EaD para sua FC em enfoques construtivistas e remotos do laboratório didático de ciências. Neste sentido, a tabela 3 representa nesta pesquisa uma síntese do processo contínuo da apropriação do enfoque epistemológico e remoto no ensino de ciências, medido através da qualidade das UEPS construídas pelos professores que apresentaram as versões 1 e 2 completas de acordo com as orientações socializadas na estratégia se EAD.

Tabela 3: estimação global de qualidade das UEPS construídas por oito dos professores participantes sobre o enfoque epistemológico e remoto no ensino de ciências. Fonte: os pesquisadores.

\begin{tabular}{|c|c|c|c|c|}
\hline \multirow[b]{2}{*}{$\begin{array}{l}\text { Professor/ } \\
\text { temática }\end{array}$} & \multicolumn{2}{|c|}{ I versão UEPS } & \multicolumn{2}{|c|}{ II versão UEPS } \\
\hline & $\begin{array}{l}\text { Estimação de } \\
\text { qualidade }\end{array}$ & $\begin{array}{l}\text { Ponderação } \\
\text { (X/10pts) }\end{array}$ & $\begin{array}{l}\text { Estimação de } \\
\text { qualidade }\end{array}$ & $\begin{array}{l}\text { Ponderação } \\
\text { (X/10pts) }\end{array}$ \\
\hline $\begin{array}{c}\text { I/ } \\
\text { Biodescontaminação }\end{array}$ & Baixa qualidade & 4,5 & Boa qualidade & 7,3 \\
\hline $\begin{array}{c}\text { II / } \\
\text { Saneamento da água }\end{array}$ & $\begin{array}{l}\text { Excelente } \\
\text { qualidade }\end{array}$ & 9,1 & $\begin{array}{l}\text { Excelente } \\
\text { qualidade }\end{array}$ & 10 \\
\hline $\begin{array}{c}\text { III / } \\
\text { Geoquímica do solo }\end{array}$ & Baixa qualidade & 3,6 & Boa qualidade & 6,7 \\
\hline $\begin{array}{l}\text { IV / } \\
\text { Observação de } \\
\text { tecidos animais }\end{array}$ & Boa qualidade & 6,3 & $\begin{array}{l}\text { Excelente } \\
\text { qualidade }\end{array}$ & 9,0 \\
\hline $\begin{array}{c}\text { VI / } \\
\text { Árvores filogenéticas }\end{array}$ & Boa qualidade & 6,3 & Boa qualidade & 7,8 \\
\hline $\begin{array}{c}\text { VII / } \\
\text { Observação de células } \\
\text { de câncer }\end{array}$ & Boa qualidade & 7,1 & $\begin{array}{l}\text { Excelente } \\
\text { qualidade }\end{array}$ & 9,3 \\
\hline $\begin{array}{c}\text { VIII } \\
\text { Reino Protoctista }\end{array}$ & Boa qualidade & 6,7 & $\begin{array}{l}\text { Excelente } \\
\text { qualidade }\end{array}$ & 9,1 \\
\hline
\end{tabular}

Na tabela 3 é possível identificar três níveis de qualidade das UEPS, que estão relacionados com o nível de correspondência das construções dos professores com tendências de ensino, identificadas como tendências tradicionalistas e tendências construtivistas (como por exemplo o enfoque epistemológico) de ensino de ciências no laboratório didático de ciências. Assim, nesta pesquisa, uma UEPS nominada de baixa qualidade tem elementos consistentes com o enfoque tradicional de ensino de ciências no LDC; uma UEPS de boa qualidade reúne alguns elementos que dialogam com uma didática baseada em enfoques construtivistas e remotos; e uma UEPS de excelente qualidade contém uma didática baseada na resolução de problemas de natureza socio-científicos com propostas de abordagens situadas em atividades experimentais remotas.

Um dos elementos mais ressaltantes das UEPS construídas por estes grupos de professores tem a ver com o fato de coincidir com a necessidade de se apropriar de novas estratégias de ensino no cenário pandêmico atual que permitam facilitar aprendizagens de forma remota, assim os laboratórios remotos foram levados em consideração pelos professores como estratégias de ensino que vêm democratizar o acesso de estudantes ao processo de experimentação didática, fundamental no ensino de ciências (SILVA, BILESSIMO, SCHEFFER, e SILVA, 2020).

Outro aspecto recorrente encontrado no processo de análise das UEPS foi a manifestação dos professores de partir de questões problemáticas surgidas do contexto dos 
estudantes, com uma proposta de abordagens no desenvolvimento de atividades experimentais remotas. Coincidindo com Borges (2002), os professores entendem a necessidade de construir propostas que permitam inserir os estudantes em situações problemáticas reais, com um amplo grado de liberdade no momento de compressão e seleção de procedimentos mais apropriados durante a experimentação didática.

Por fim, os pesquisadores coincidem na resistência inicial que ainda hoje têm os professores de ciências em aprender desde uma perspectiva significativa novas estratégias e enfoques de abordagem construtivistas para ensinar ciências no LDC, baseados em resolução de problemas com abordagens remotas, devido ao conflito natural no qual são enfrentadas suas posições tradicionalistas, cristalizadas no positivismo lógico, com as propostas educacionais centralizadas em posições construtivistas, relativistas e remotas.

\section{Considerações finais}

O cenário pandêmico atual é sumamente complexo, mas não socavou o espírito do professor de ciências em relação à sua eminente vontade de procurar novas ferramentas e estratégias didáticas que auxiliem sua práxis pedagógica. De fato, os professores de ciências participantes deste estudo entendem que o confinamento social representou, entre outras coisas, um momento para fortalecer sua formação continuada em abordagens e novas estratégias que gerem suporte e contribuições importantes no ato de ensinar ciências à distância.

Os professores de ciências desenvolveram mudanças favoráveis e consistentes com as tendências atuais mais amplamente aceitas sobre o papel da experimentação didática no ensino de ciências, baseados nas evidências de aprendizagem significativa coletadas e analisadas nesta pesquisa, as quais expressarão um alto nível de qualidade das suas produções didáticas sobre o enfoque epistemológico e de experimentação remota do ensino de ciências.

Mantém-se neste estudo a relevância educacional dos Laboratórios Remotos, pelas oportunidades que oferece no processo de democratização e ampliação no acesso estudantil à experimentação didática, sendo conceitualizados como estratégias didáticas que ampliam as possibilidades de acesso e manipulação de experimentos reais a partir do acesso à internet. Não obstante, o sucesso da implementação desta estratégia dependerá não só do acesso às tecnologias, mas também de um processo amplo e integrado de alfabetização tecnológica dos professores e seus estudantes.

Finalmente, acreditamos que é necessário continuar pesquisando nesta linha, mediante a indagação das seguintes dimensões: potencialidades didáticas dos laboratórios remotos no ensino de ciências, formação continuada do professor de ciências e tendências construtivistas de ensino de ciências.

\section{Referências}

ANDRES, M; PESA, M: MOREIRA, M. (2007). El trabajo de laboratorio en cursos de física desde la teoría de campos conceptuales. Ciência \& Educação, 12 (2), pp.129-142. DOI:

http://dx.doi.org/10.1590/S1516-73132006000200002. 
BARBERÁ, O. \& VALDÉS, P. (1996). El trabajo práctico en la enseñanza de las ciencias: una revisión. Enseñanza de las Ciencias, 14 (3), pp. 365-379.

BAROLLI, E.; LABURU, C. E. \& GURIDI, V. M. (2010). Laboratorio didáctico de ciencias: caminos de investigación. Revista Electrónica de Enseñanza de las Ciencias, 9 (1), pp. 88-110.

BORGES, A. T. (2002). Novos Rumos para o laboratório escolar de ciências. Caderno Brasileiro de Ensino de Física. 19 (3), pp. 291-313.

CACHICHI, R. C., JUNIOR, G. G, AUTOR 2, JUNIOR, J. A. M. S, GOMES, D. F. \& SIMONI, J. DE A. (2020) Creation of a Phenol/Water Phase Diagram Using a Low-Cost Automated System and Remote Transmission. Journal of Chemical Education, 97 (10), pp. 3667-3672. DOI: http://dx.doi.org/10.1021/acs.jchemed.0c00070.

AVILES; I. E; GALEMBECK, E. (2019). Concepciones epistemológicas y visiones pedagógicas sobre la enseñanza y el aprendizaje de las ciencias: el caso de profesores de Brasil y Venezuela. Investigações em Ensino de Ciências, 24 (2). DOI: http://dx.doi.org/10.22600/15188795.ienci2019v24n2p256.

AVILES; I. E. (2020). Aprendizagem significativa por meio da experimentação epistemológica com laboratórios remotos. Tese (doutorado) - Universidade Estadual de Campinas, Instituto de Física Gleb Wataghin, Campinas, SP.

AVILES; I. E; GALEMBECK, E. (2020). UEPS sobre el enfoque epistemológico y remoto del laboratório didáctico: evidencias de aprendizaje significativo de professores de ciências. Aprendizagem Significativa em Revista, 10 (1), pp. 33-45.

AVILES; I. E; GALEMBECK, E. (2017). Laboratorio constructivista y remoto: secuencia didáctica potencialmente significativa para la formación continuada del profesor de ciencias en Latinoamérica. Enseñanza de las Ciencias, Núm. Extra, pp. 2485-2490.

AVILES; I. E; FLORES, J; GALEMBECK, E. (2020). El papel de la experimentación didáctica en la enseñanza de las ciencias: evidencia del aprendizaje significativo de sus maestros. Amazônia: Revista de Educação em Ciências e Matemáticas, 16 (36), pp. 53-65.

DECRETO No 9.057, DE 25 DE MAIO DE 2017. Regulamenta o art. 80 da Lei no 9.394, de 20 de dezembro de 1996, que estabelece as diretrizes e bases da educação nacional.

FLORES, J., CABALLERO, M. \& MOREIRA, M. A. (2011). Construcción de un marco teórico/conceptual para abordar el trabajo de laboratorio usando el diagrama $V$ un estudio de caso de la UPEL/IPC. Revista de Investigación, 35 (73), pp. 241-266.

FLORES, J; CABALLERO, C \& MOREIRA, M. A. (2014). Los mapas conceptuales como ins trumentos evaluativos del nivel de construcción integrativa de significados en el laboratorio de bioquímica bajo un enfoque constructivista. Investigações em Ensino de Ciências, 19 (3), pp. 611-624.

FLORES, J., SAHELICES, C., CONCESA, M., \& MOREIRA, M. A. (2009). El laboratorio en la enseñanza de las ciencias: Una visión integral en este complejo ambiente de aprendizaje. Revista de Investigación, 68, pp. 75-111.

FUNDAÇÃO CARLOS CHAGAS. (2020). Educação escolar em tempos de pandemia na visão de professoras/es da Educação Básica. Disponível em https://www.fcc.org.br/fcc/educacaopesquisa/educacao-escolar-em-tempos-de-pandemia-informe-n-1 
GRECA, E., MENESES, J. E DIEZ, M. (2017). A formación en ciencias de los estudiantes del grado en maestro de Educación Primaria. Revista Electrónica de Enseñanza de las Ciencias, 16 (2), pp. 231-256.

HODSON, D. (1994). Hacia un enfoque más crítico del trabajo de laboratorio. Enseñanza de las Ciencias, 12 (3), pp. 299-313.

HOFSTEIN, A. (2004). The laboratory in chemistry education: thirty years of experience with developments, implementation, and research. Chemistry Education: Research and Practice, 5(3), 247-264 (8)

HOFSTEIN, A. \& LUNETTA, V, N. (2004). The laboratory in science education: Foundation for the 21st century. Science Education, 88, 28-54. doi:10.1002/sce.10106

INSTITUTO PENÍNSULA. (2020). Sentimento e percepção dos professores brasileiros nos diferentes estágios do Coronavírus no Brasil. Disponível em:

https://institutopeninsula.org.br/wp-content/uploads/2020/05/ Pulso-Covid-19_-InstitutoPenínsula.pdf

MORAES, R. (2003). Uma tempestade de luz: a compreensão possibilitada pela análise textual discursiva. Ciência e Educação, n. 2, p.191-210.

MOREIRA, Marco. (2013). Aprendizagem significativa, organizadores prévios, mapas conceituais, diagramas v e unidades de ensino potencialmente significativas. Disponível em: http://www.profjudes.unir.br/uploads/44444444/arquivos/TAS_1490483223.pdf

MOREIRA, M. A. (2012). Mapas Conceituais e aprendizagem significativa. Disponível em: https://www.if.ufrgs.br/ moreira/mapasport.pdf

MORENO-RODRIGUES, A. S. \& MASSENA, E. P. (2020). Cooperação latino-americana para a formação de professores de ciências. https://doi.org/10.1590/21172020210143

NOVAK, J \& CAÑAS, A. (2020, jan-jun.). A Teoria Subjacente aos Mapas Conceituais e como elaborá-los e usá-los. Práxis. Educativa, Ponta Grossa, v.5, n.1, p. 9-29.

SILVA, J. B. da, BILESSIMO, S. M. S, SCHEFFER, G. R.\& SILVA, I. N. da. (2020). Laboratórios Remotos como Alternativa para Atividades Práticas em Cursos na Modalidade EAD. EaD Em Foco, 10(2). https://doi.org/10.18264/eadf.v10i2.942 